\title{
Travel Time and Congestion Assessment Along Ujala Circle (S.G. Highway Ahmedabad)
}

\author{
Vivek Mer, V.R. Patel, A.K. Patel
}

\begin{abstract}
The approximately 25201084 (2018) vehicular citizenry in Ahmedabad city so it is very necessary to negotiate its movements and infirmity effects like as air and noise pollution \& other environment effects, traffic congestion, time loss, and so on. S.G Highway has $44.5 \mathrm{~km}$ long stretch of Ahmedabad, an oldest and most substantial stretch which started from Ujala circle. For declamation the traffic congestion, classified volume count survey (by Video Graphic method), travel time and delay survey (by Moving Observer Method), and for speed-flow-density relationship Spot speed study at Ujala circle during Friday has been accomplished and analyzed. From the calculated data, graph of flow $v / s$ density, speed $v / s$ density and speed $v / s$ flow relationship has been prosecute with the $R^{2}$ value of each relationship. This analysis proved that current traffic situation at Ujala circle is highly congested, which leads to the higher travel time taken by vehicle compare to free flow condition. From all analyzed data, alternate invigorating measures are prospected. Based on those alternative invigorating measures best alternative is choose as well as bring off simulation and validation of Model in the VISSIM software, also design in AutoCAD for better illustration of issue.
\end{abstract}

Keywords: Travel Time, Congestion, VISSIM, Auto CAD, Simulation, Validation, Model, Traffic.

\section{INTRODUCTION}

$\mathrm{E}_{\text {xpeditious growth in the urbanization during the Past two }}$ decades has been increased in our country. This reason leads to the demand of transportation facilities which are the basic requirement of our country's urban population is rising enormously. More people are entrained to gain employment for living better quality of life that's why the growth of the urban population is upsurge so ultimately boosting the urbanization. As the urbanization increases the industrialization of some region also expanse so per capita income will also magnify that's why people will utilize their own vehicle to travel from origin to destination. In fact, the

Revised Manuscript Received on June 15, 2020.

* Correspondence Author

Vivek Mer*, PG Student, Department of Civil Engineering, P.G. Center of Transportation Engineering, L.D. College of Engineering Ahmedabad, Gujarat. Email: vivekmer78@gmail.com

D.R. V.R. Patel, Associate Professor, Department of Civil Engineering, L.D. College of Engineering Ahmedabad, Gujarat. Email: vrpatel@ldce.ac.in

D.R. A.K. Patel, Assistant Professor, Department of Civil Engineering, Government Polytechnic Ahmedabad, Gujarat. Email: ashutech.asp@gmail.com

(c) The Authors. Published by Blue Eyes Intelligence Engineering and Sciences Publication (BEIESP). This is an open access article under the CC BY-NC-ND license (http://creativecommons.org/licenses/by-nc-nd/4.0/) growth rate of the country's economic development hoist too fast and sometimes much faster than infrastructure development causing limited road space to deal with personalized vehicles so this reason leads to the increasing road capacity also increasing congestion and delay that is major reason behind the accidents. It has been concluded that traffic accidents are among the primary cause of accidental deaths in Indian cities. The premier cause of these of these trouble is the case of variance in modal split and inadequate transportation infrastructure. Public transportation deteriorate to keep same level with quick and considerable rise in demand over past few decades.

The best strategy to meet the growing urban travel demand in a sustainable manner is to convince people with reasoning to shift from personalized vehicles to public transportation. This is because public transportation occupies less road space, consumes less fuel and emits fewer pollutants as compared to any other motorized modes of travel.

Ujala circle is one of the most developed and important starting point of S.G. Highway link, which serve all major activities, industrialization activities, travelling and transportation activities, academic activities etc. that is reflecting the culture of metropolitan city in Gujarat.

\section{AIM OF STUDY}

The aim of study is to find out traffic volume, travel time and spot speed under current traffic situation in Ujala circle (S.G. Highway), after analyze it so that we can contemplate remedial measure in current traffic situation.

\section{OBJECTIVES}

1) To find out Classified Volume Count by Videography Method.

2) To determination of Travel time $\&$ delay by Moving Observer method.

3) To elaborate Speed-Flow Density relationship

4) To obtain actual traffic model, simulation, and evaluation in VISSIM software.

5) To furnish viability checks other alternatives.

\section{SCOPE OF WORK}

1) Planning for smart mobility at Ujala circle encouraging pedestrians and cyclists (no tax) with proper facilities.

2) Redesigning of critical junction like Ujala circle.

3) Conversion of un signalized intersection to signalized intersection.

Published By:

Blue Eyes Intelligence Engineering

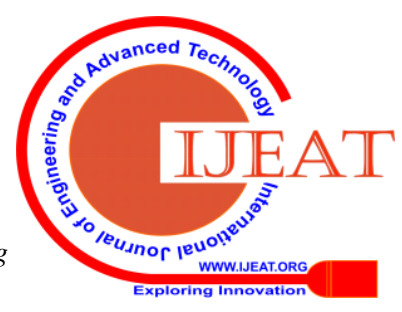


4) Construction of Elevated bridge to counteract heavy traffic and we could achieve control over congestion.

5) Parking management plan can be develop.

6) Relocation of traffic generating informal activities.

\section{LITERATURE REVIEW}

Traffic congestion does not possess any exact or broadly accepted definition, but in simply words we could say that "Traffic Congestion is phenomenon wherever demand exceeds the capacity of the transportation system". Also traffic congestion can be defined in the following two ways: (civil.iitb.ac.in/tvm/nptel by Prof. Tom V. Mathew)

1. Congestion is the travel time or delay in excess of the normally incurred under light or free flow traffic condition.

2. Unacceptable congestion is travel time or delay in excess of agreed norm which may vary by type of transport facility, travel mode, geographical location, and time of delay.

The basic cause of traffic congestion is progression of society, economy and technology, house hold characteristics which leads to the change in transportation system. This change cause diversity in transport behavior, locational pattern and other agglomeration effects result in the growth of traffic. The growth of traffic being continuous and finally situation arises where traffic growth exceeds capacity of transportation system. Which finally leads congestion. Congestion has a different infirmity effect over drivers, environment, health and economy. So that encounter of traffic congestion is mandatory by proper analysis and following supreme remedial measure.

\section{A. Travel Time Study}

Travel time can be defined as the time period required to travel on desired routes between any two points of interest. Travel time is essential measure transportation engineering commonly used in wide range of transportation analysis including transportation planning, congestion analysis, traveler information. In briefly Travel time study has highly significance in traffic control, highway improvements and document congestion. For accurate analysis of travel time \& delay study Moving Observer method is used. Data obtained from travel time and delay studies give a good indication of the level of service (LOS) on the study section, therefore data obtain from this study gives brief information for identifying critical locations, which may require special attention in order to improve the overall traffic flow in the route.

\section{B. Moving Observer Survey}

In this method observer sitting in car and car is moving in direction of stream from origin (south) to destination (north). During this journey note down Number of overtaking vehicle, Number of overtaken vehicle, Average number of vehicle in opposite direction $\left(\mathrm{m}_{\mathrm{a}}\right)$, Average journey time when vehicle is travelling in the stream $\left(t_{w}\right)$, Average journey time when vehicle is travelling in opposite stream $\left(\mathrm{t}_{\mathrm{a}}\right)$, Delay time. Let's give the name of trip as S-N trip. Similarly carried out N-S trip and note down same parameters mentioned above.

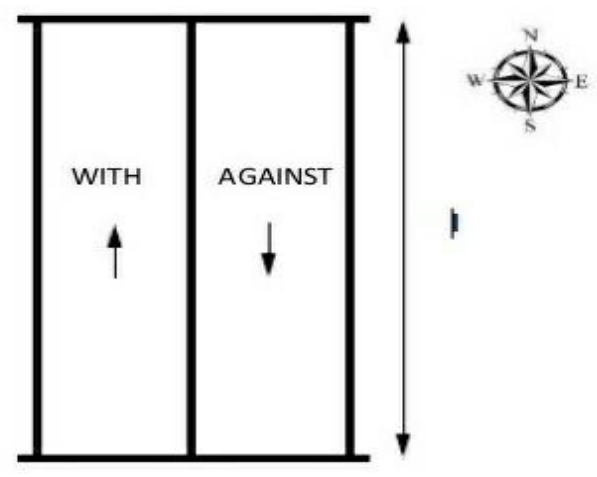

Fig. 1 Moving Observer Survey

Source: https://www.google.co.in/

Following equation could be developed from the derived parameters, after that calculate average Journey speed and average running speed.

$\mathrm{m}_{\mathrm{w}}=$ Overtaking vehicle - Overtaken vehicle

Flow $(\mathrm{q})$ veh $/ \mathrm{min}=\left[\left(\mathrm{m}_{\mathrm{w}}+\mathrm{m}_{\mathrm{a}}\right) /\left(\mathrm{t}_{\mathrm{w}}+\mathrm{t}_{\mathrm{a}}\right)\right]$

Average Journey Time $=\left[\mathrm{t}_{\mathrm{w}}-\left(\mathrm{m}_{\mathrm{w}} / \mathrm{q}\right)\right]$

Average running time $=$ Average journey time -

Average stopped delay

\section{Classified Volume Count}

For determination of the number, movements, and classifications of roadway vehicles at a given location Traffic volume studies are very important. These data helps to identify critical flow time periods, determining the influence of large vehicles or pedestrians on vehicular traffic flow. Methods of volume count and intended use of volume recorded data decides the length of sampling period. Basically there are two ways to carried out volume count, 1) Manual count 2) Automatic count. For collecting small samples of data any given location manual count is most applicable. Also for collecting sample data less than 1 day manual count is appropriate. Normal interval for a manual count are 5, 10, 15 minutes. Traffic count during bottleneck condition like Monday morning, and Friday evening manual count is not appropriate. Data collection by manual count can be expensive in terms of manpower. At the intersection manual count is generally tedious because vehicle on each arm should be counted and recorded separately for each movement. Determination of volume count by automatic count can be done by permanent counters, portable counters or videography. At a place where large amount of vehicular gathering is found volume count by automatic count is appropriate. Automatic counts are usually taken in 1-hour interval for each 24-hour time period and from that peak hour can easily be identified. The count may be extend for week, month, or year also.

\section{Spot Speed Survey}

In a simply word spot speed can be defined as a instantaneous speed of vehicle at a particular location. Spot speed can be used to design the geometry of road like horizontal and vertical curves, Super elevation etc.

Published By:

Blue Eyes Intelligence Engineering

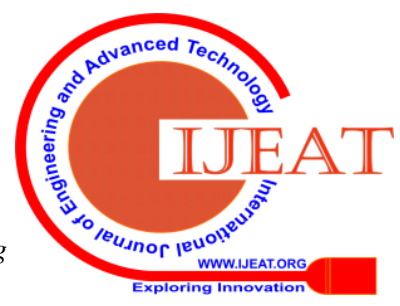


In Location and size of signs. Design of signals, accident analysis, road maintenance and congestion analysis, spot speed data plays as a role of basic input. Spot speed can be determined by using an enoscope or pressure contact tubes. But here we were calculated spot speed by videography in which we calculated time required for at least 5 vehicle in one minute to cross 20 meter stretch and just simply done $20 \mathrm{~m} /$ time and get spot speed for 20 meter stretch in 1 minute.
1) Arterial: No frontage access, no standing vehicles, very little cross traffic

2) Sub-arterials: Frontage development, side roads, bus stops, no standing vehicles, waiting restrictions.

3) Collectors: Free frontage access, parked vehicles, bus Stops, no waiting restrictions.

\section{E. Design Service Volumes of Urban Roads}

Recommended design service volumes in PCU per hour for urban roads like Arterial, Sub-arterial and Collector shown in Table 1.

Table 1 Recommended Design Service Volumes ( PCU per Hour)

\begin{tabular}{|c|c|c|c|c|}
\hline Sr. No. & Type of carriageway & \multicolumn{2}{|c|}{} \\
\cline { 2 - 4 } & & Arterial & Sub-arterial & Collector \\
\hline 1. & 2-Lane (One-Way) & 2400 & 1900 & 1400 \\
\hline 2. & 2-Lane (Two-Way) & 1500 & 2900 & 2200 \\
\hline 3. & 3-Lane (One-Way) & 3600 & 2400 & 1800 \\
\hline 4. & 4-Lane Undivided (Two-Way) & 3000 & 2900 & - \\
\hline 5. & 4-Lane Divided (Two-Way) & 3600 & 3800 & - \\
\hline 6. & 6-Lane Undivided (Two-Way) & 4800 & 4300 & - \\
\hline 7. & 6-Lane Divided (Two-Way) & 5400 & - \\
\hline
\end{tabular}

Source: Guidelines for Capacity of Urban Roads in Plan Areas, IRC 106-1990

\section{STUDY AREA ILLUSTRATION}

Ahmedabad is one of the wide-ranging city and former capital of the Indian state of Gujarat. Ahmedabad is placed on the bank of the Sabarmati River of $23 \mathrm{~km}$, from the state capital Gandhinagar, which is its twin city. Ahmedabad's population of 7.8 million (as per 2020 population census) makes it the fifth-most populous city in India. Vehicular population in Ahmedabad city is 25201084 (2018-2019) which is comparatively large over the area of $464.16 \mathrm{~km}^{2}$ of Ahmedabad city. Ahmedabad is $14^{\text {th }}$ most cleanest city in India. Some oldest name of Ahmedabad city is "ashaval" also during $15^{\text {th }}$ century it's well known as "karnavati". Ahmedabad mostly known for tourist attraction, street food places, diamond cutting and much more. Ujala circle consider as a starting node of S.G. Highway, and S.G. Highway is well known for most congested highway which connects two major cities like Ahmedabad and Gandhinagar. Ujala circle consist of three major roads,
1) Ujala circle to S.G. Highway
2) Ujala circle to Ujala bridge
3) Ujala circle to Sarkhej bavla road.

Among this three roads Ujala circle to S.G. Highway road possess sufficient width so there is not arise much problem of congestion while vehicle moving towards S.G. Highway. But due to the limited road width at Ujala circle to ujala bridge and Ujala circle to sarkhej bavla road there is arise problem of congestion while vehicle moving towards ujala bridge and sarkhej bavla road respectively.

\section{A. Road Inventory}

Ujala circle is one of the most developed and important starting node of S.G. Highway link, which serve all major

activities, industrialization activities, residential activities, travelling and transportation activities, academic activities etc, that is reflecting the culture of metropolitan city in Gujarat.

Because of this mix activities traffic congestion arises regularly.

Road inventory is given in table 2 and road section shown in figure 4 \& 5

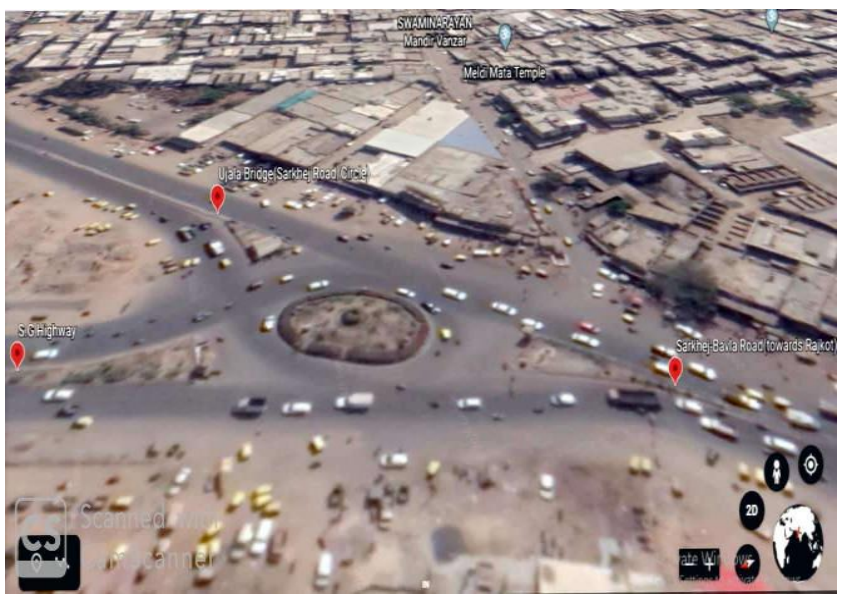

Fig. 2 Survey Locations (Source: Google Earth)
Published By:

Blue Eyes Intelligence Engineering \& Sciences Publication

(C) Copyright: All rights reserved. 
Travel Time and Congestion Assessment Along Ujala Circle (S.G. Highway Ahmedabad)

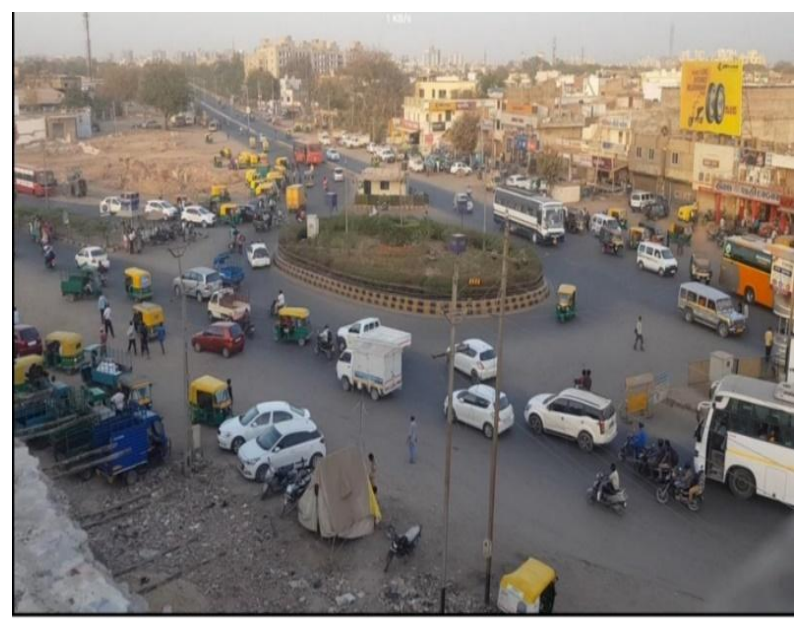

Fig. 3 Ujala Circle Area

Table 2 Road inventory of study area

\begin{tabular}{|c|c|c|}
\hline Name of area & Ujala circle to Ujala bridge, Ujala circle to Sarkhej bavla road & $\begin{array}{c}\text { Ujala circle to S.G. } \\
\text { Highway }\end{array}$ \\
\hline Type of road & Divided & Divided \\
\hline Right of way & $53 \mathrm{~m}$ & $60 \mathrm{~m}$ \\
\hline Width of the carriageway & $7.5 \mathrm{~m}$ & $10.5 \mathrm{~m}$ \\
\hline Width of footpath & $4 \mathrm{~m}$ & $4 \mathrm{~m}$ \\
\hline
\end{tabular}

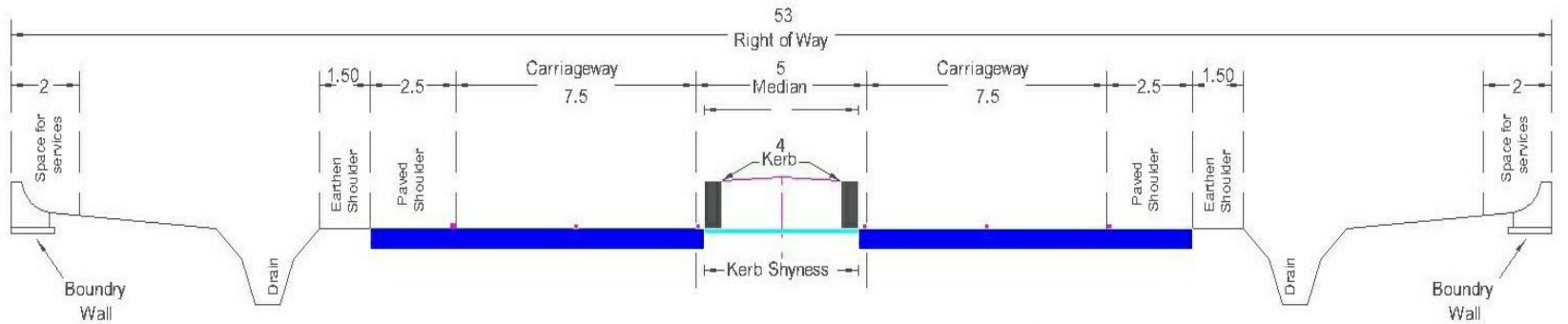

Fig 4 Section view of Ujala circle to Ujala bridge \& Ujala circle to Sarkhej-bavla road

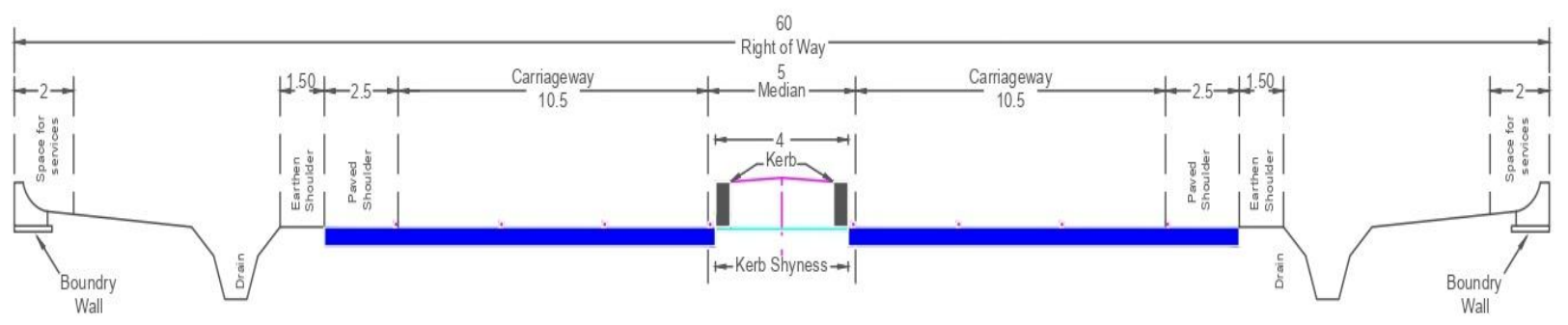

Fig 5 Section view of Ujala circle to S.G. Highway

\section{DATA COLLECTION AND ANALYSIS}

\section{A. Classified Volume Count}

Classified volume count survey is carried out using videography on Friday. On Friday survey is done for 6 hour which consist 3 hour of morning peak and 3 hour of evening peak. Vehicle counts are carried out at three routes.

1) Total number of vehicle moving towards Sarkhej-Bavla Road

2) Total number of vehicle moving towards Ujala Bridge.

3) Total number of vehicle moving towards S.G. Highway.

\section{B. Moving Observer Method}

This survey is carried out here for 3 stretches.

1) Ujala circle to Santhal circle,

2) Ujala circle to Sarkhej circle

3) Ujala circle to Sanand Chokdi.

While performing this survey at least 5 trips are required for particular stretch when vehicle moving from origin to destination. The area of interest while performing this survey is to find out Average journey time, Average running time and delay. Figure 8 . Shows moving observer survey results during morning and evening peak hour for all this three interested stretches.

\section{Published By:}

Blue Eyes Intelligence Engineering

\& Sciences Publication

(C) Copyright: All rights reserved.

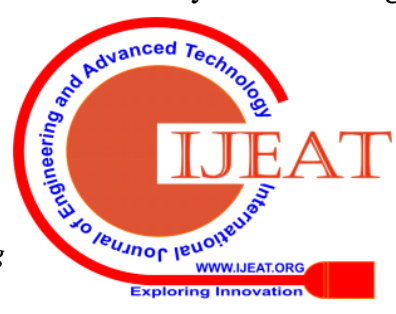




\section{Spot Speed Survey}

Here Relationship between Speed, Flow, Density is developed by using equation (5) and create diagrams like Flow-Density, Speed-Density and Speed Flow as shown in figure 9.In this Survey videography is analyze in AVIDMUX
Software to determine vehicular time to reach from origin to destination.

The data are shown in table number 4, 5, and 6 .

$\mathrm{q}=\mathrm{k} \mathrm{v} \quad \ldots . .(5)$

Where $\mathrm{q}=$ Flow, k= Density, $\mathrm{v}=$ Average Speed

Table 3 Classified Volume Count (PCUs)

\begin{tabular}{|l|c|l|l|l|l|l|}
\hline \multicolumn{1}{|c|}{ Locations } & Morning & \multicolumn{3}{l|}{ Evening } \\
\cline { 2 - 7 } & 10 to 11 & 11 to 12 & 12 to 01 & 04 to 05 & 05 to 06 & 06 to 07 \\
\hline At Sarkhej Bavla Road to S.G. Highway & 1243.5 & 1254 & 1262.5 & 1154 & 1189 & 1156.5 \\
\hline At Sarkhej Bavla Road to Ujala Bridge & 1345.5 & 1629 & 1521 & 1411.5 & 1477.5 & 1484.5 \\
\hline At Ujala Bridge to S.G. Highway & 1282 & 1345.5 & 1359.5 & 1324.5 & 1397 & 1400.5 \\
\hline At Ujala Bridge to Sarkhej Bavla Road & 1624.5 & 1616 & 1633 & 1644 & 1644.5 & 1646 \\
\hline At S.G. Highway to Ujala Bridge & 535 & 576 & 630 & 527 & 582.5 & 604 \\
\hline At S.G. Highway to Sarkhej Bavla Road & 1535 & 1599.5 & 1647 & 1576.5 & 1571 & 1628 \\
\hline
\end{tabular}

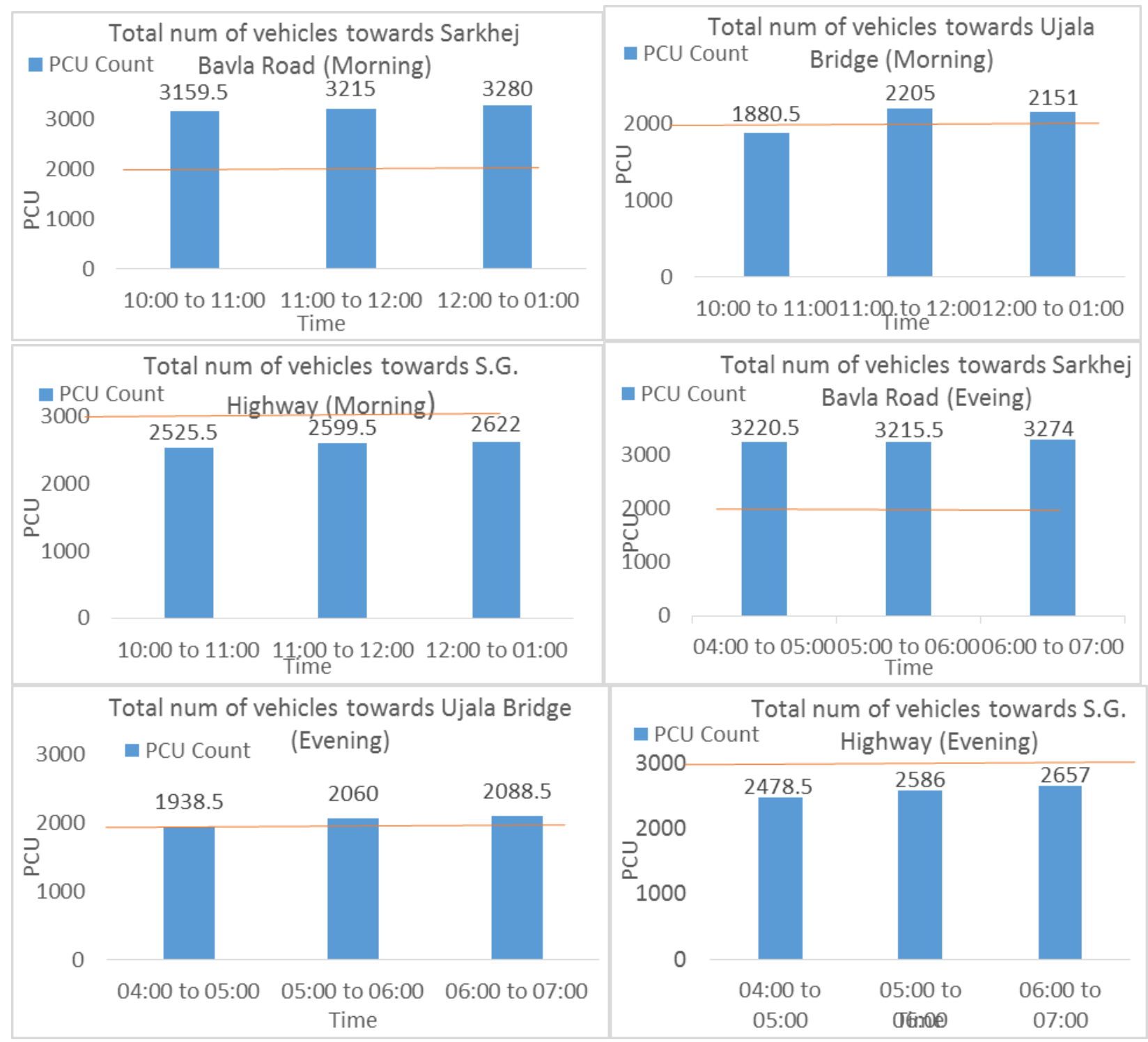

Fig 6 Classified Volume Count in PCUs at Ujala Circle

Horizontal Red line indicate PCU Carrying Capacity limit as per IRC 106-1990

Published By:

Blue Eyes Intelligence Engineering

\& Sciences Publicati

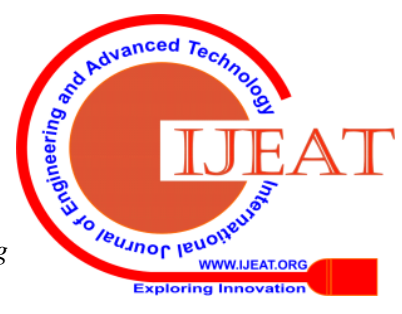


Travel Time and Congestion Assessment Along Ujala Circle (S.G. Highway Ahmedabad)

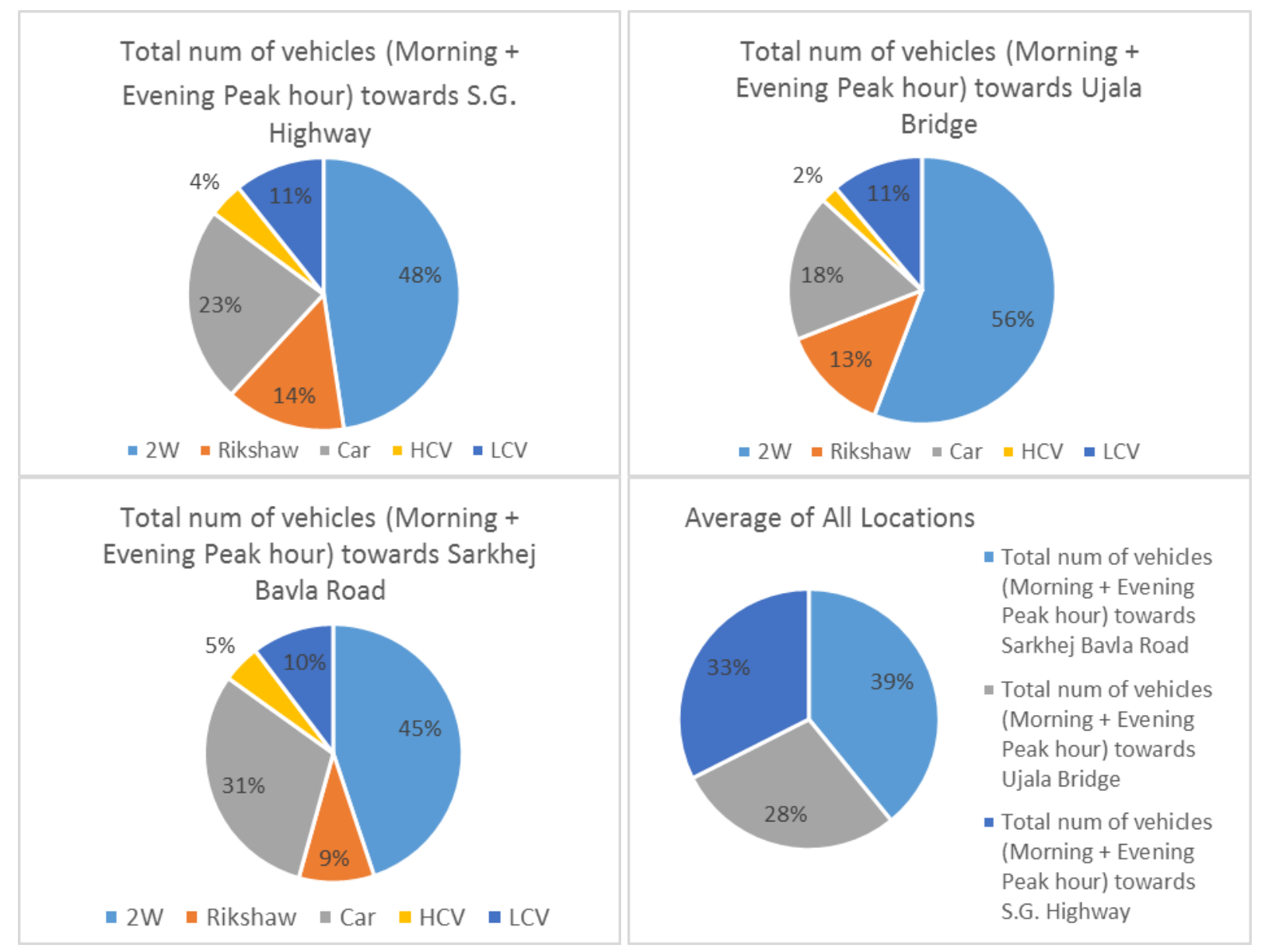

Fig 7 Total Vehicle Composition at Ujala Circle

Table 4 Calculation of fundamental parameters towards Sarkhej-bavla road

\begin{tabular}{|c|c|c|c|}
\hline Time & Avg. Speed $(\mathrm{km} / \mathrm{hr})$ & Flow $(\mathrm{PCU} / \mathrm{hr})$ & Density $($ PCU/km) \\
\hline $10: 00-10: 05$ & 39.28 & 3243.5 & 82.57 \\
\hline $10: 05-10: 10$ & 38.27 & 2917 & 76.22 \\
\hline $10: 10-10: 15$ & 34.38 & 3218 & 93.6 \\
\hline $10: 15-10: 20$ & 36.11 & 2992 & 82.86 \\
\hline $10: 20-10: 25$ & 35.77 & 3117.5 & 87.15 \\
\hline $10: 25-10: 30$ & 35.14 & 3376.5 & 96.087 \\
\hline $10: 30-10: 35$ & 33.44 & 3092.5 & 92.47 \\
\hline $10: 35-10: 40$ & 32.49 & 3520 & 108.38 \\
\hline $10: 40-10: 45$ & 36.08 & 3067.5 & 85.02 \\
\hline $10: 45-10: 50$ & 36.28 & 3369 & 92.86 \\
\hline $10: 55-10: 55$ & 35.89 & 3067.5 & 85.46 \\
\hline
\end{tabular}

Table 5 Calculation of fundamental parameters towards Ujala Bridge

\begin{tabular}{|c|c|c|c|}
\hline Time & Avg. Speed $(\mathrm{km} / \mathrm{hr})$ & Flow (PCU/hr) & Density $($ PCU/km) \\
\hline $10: 00-10: 05$ & 19.91 & 2094 & 105.17 \\
\hline $10: 05-10: 10$ & 22.84 & 2059.5 & 90.17 \\
\hline $10: 10-10: 15$ & 20.03 & 2025 & 101.1 \\
\hline $10: 15-10: 20$ & 23.76 & 1811.5 & 76.24 \\
\hline
\end{tabular}

Published By:

Blue Eyes Intelligence Engineering

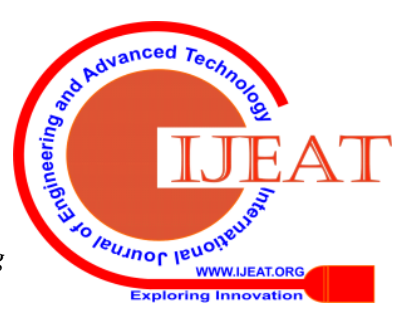




\begin{tabular}{|c|c|c|c|}
\hline $10: 20-10: 25$ & 20.52 & 1811.5 & 88.27 \\
\hline $10: 25-10: 30$ & 23.36 & 1804.5 & 77.25 \\
\hline $10: 30-10: 35$ & 21.94 & 1908.5 & 86.98 \\
\hline $10: 35-10: 40$ & 19.45 & 2052.5 & 92.53 \\
\hline $10: 40-10: 45$ & 21.19 & 1956 & 86.18 \\
\hline $10: 45-10: 50$ & 21.1 & 1818.5 & 85.59 \\
\hline $10: 50-10: 55$ & 20.2 & 1729 & 73.45 \\
\hline $10: 55-11: 00$ & 23.07 & 1694.5 & \\
\hline
\end{tabular}

Table 6 Calculation of fundamental parameters towards S.G. Highway

\begin{tabular}{|c|c|c|c|}
\hline Time & Avg. Speed $(\mathrm{km} / \mathrm{hr})$ & Flow (PCU/hr) & Density (PCU/km) \\
\hline $10: 00-10: 05$ & 29.48 & 2434 & 82.56 \\
\hline $10: 05-10: 10$ & 32.73 & 2495 & 76.23 \\
\hline $10: 10-10: 15$ & 27.11 & 2961.5 & 109.24 \\
\hline $10: 15-10: 20$ & 29.24 & 2423 & 82.87 \\
\hline $10: 20-10: 25$ & 28.95 & 2523 & 87.15 \\
\hline $10: 25-10: 30$ & 24.81 & 2378.5 & 95.87 \\
\hline $10: 30-10: 35$ & 28.42 & 2628.5 & 92.49 \\
\hline $10: 35-10: 40$ & 24.52 & 2656 & 108.32 \\
\hline $10: 40-10: 45$ & 27.52 & 2339.5 & 85.01 \\
\hline $10: 45-10: 50$ & 27.49 & 2567 & 93.38 \\
\hline $10: 50-10: 55$ & 29.9 & 2190 & 73.24 \\
\hline $10: 55-11: 00$ & 32 & 2584 & 80.75 \\
\hline
\end{tabular}
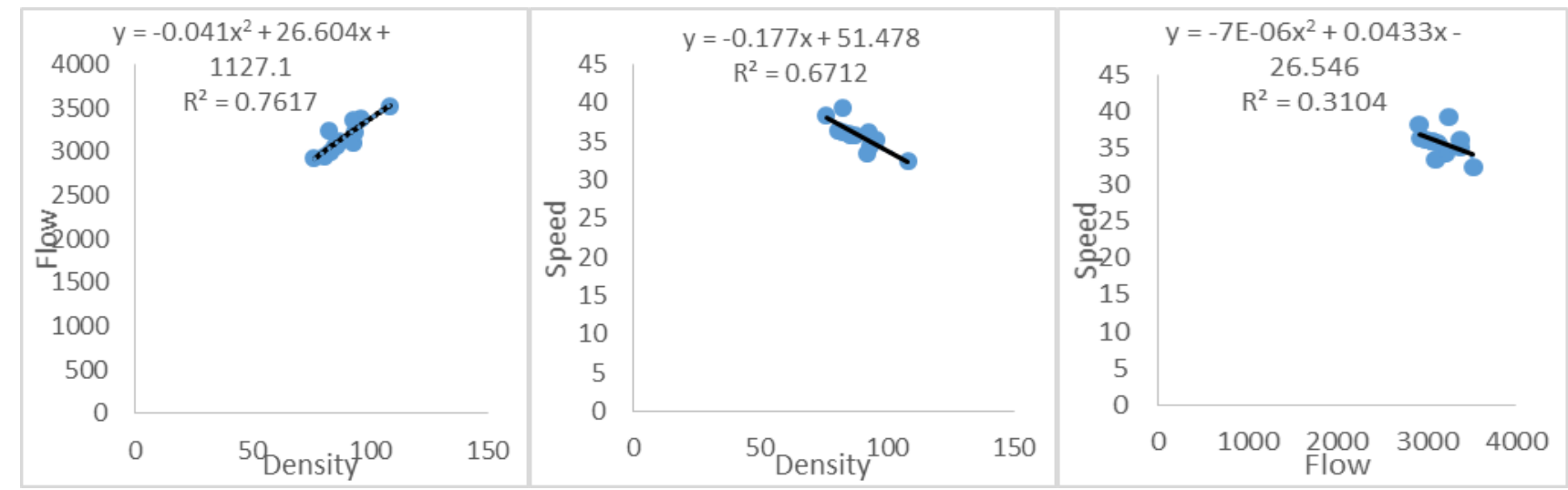

Fig 8 Flow Speed-Flow-Density Relationship for Sarkhej-Bavla Road

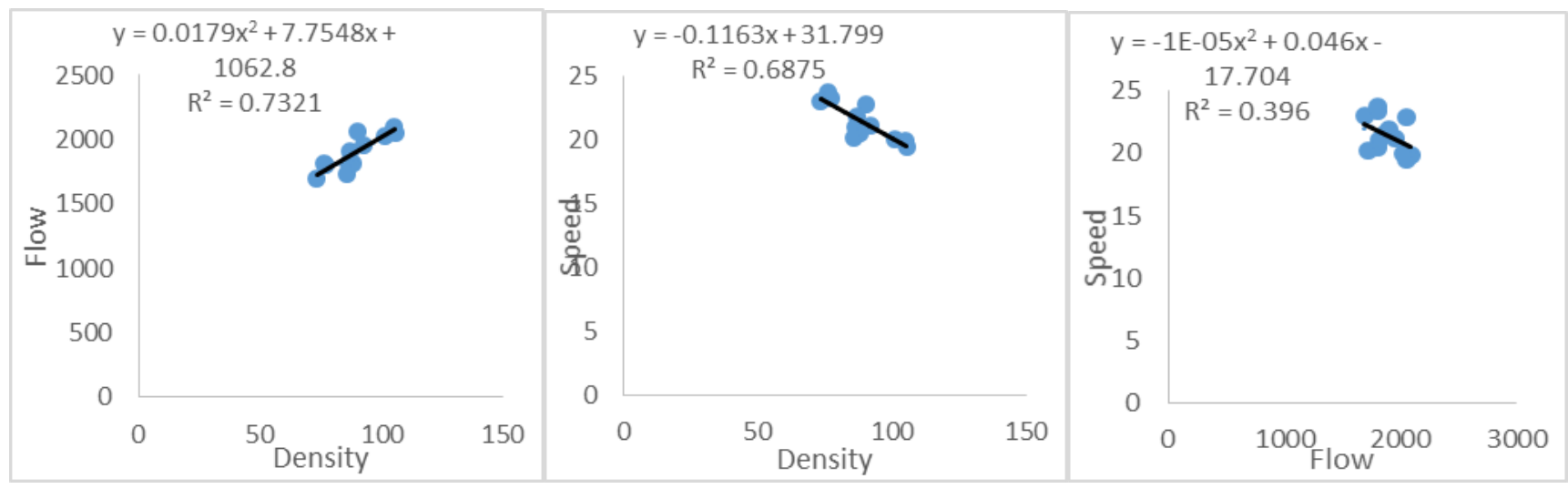

Fig 9 Flow Speed-Flow-Density Relationship for Ujala Bridge

Published By:

Blue Eyes Intelligence Engineering

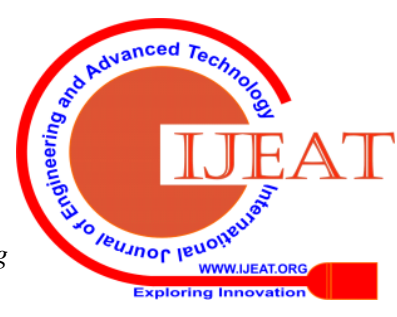


Travel Time and Congestion Assessment Along Ujala Circle (S.G. Highway Ahmedabad)

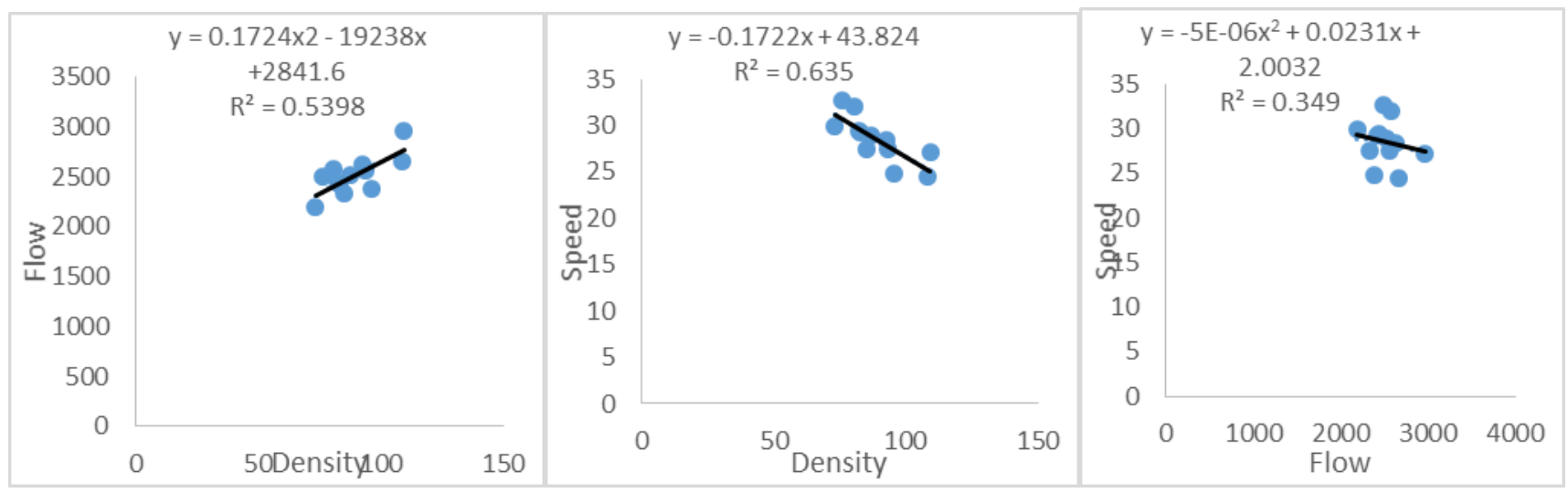

Fig 10 Flow Speed-Flow-Density Relationship for S.G. Highway

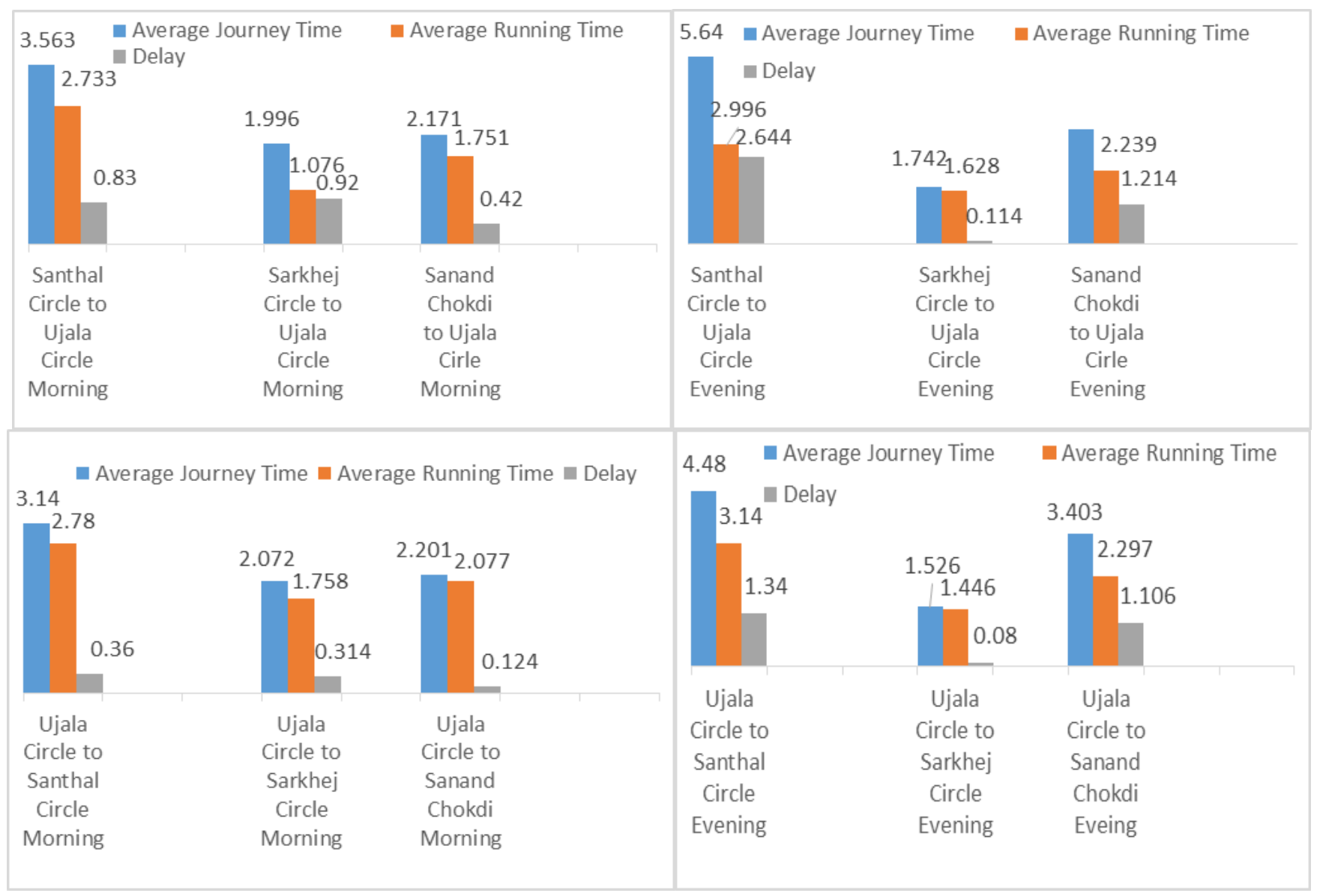

Fig 11 Moving Observer Survey Result

\section{Level of service}

We obtained Average Travel speed from the spot speed data mentioned in Table 4, 5, 6. Determine level of service for all three stretches by using Highway Capacity Manual, 2000. Level of Service E and F indicate Congestion Condition.

Table 7 Level of Service

\begin{tabular}{|c|c|c|c|}
\hline $\begin{array}{c}\text { Urban } \\
\text { Street }\end{array}$ & $\begin{array}{c}\text { Towards } \\
\text { Sarkhej-Bavla } \\
\text { Road }\end{array}$ & $\begin{array}{c}\text { Towards } \\
\text { Ujala } \\
\text { Bridge }\end{array}$ & $\begin{array}{c}\text { Towards } \\
\text { S.G. } \\
\text { Highway }\end{array}$ \\
\hline $\begin{array}{c}\text { Free } \\
\text { Flow } \\
\text { Speed }\end{array}$ & $60 \mathrm{Km} / \mathrm{hr}$ & $60 \mathrm{Km} / \mathrm{hr}$ & $80 \mathrm{Km} / \mathrm{hr}$ \\
\hline
\end{tabular}




\section{REMEDIAL MEASURES}

\section{A. Data Simulation}

Prepare actual network in form of model by using Link and Connector command. Identify vehicle routes and apply it. Feed the vehicle volume also feed the vehicle composition to individual route and apply appropriate vehicle type and vehicle class. Apply travel time command at starting and end of route between which you want to find travel time. Open Evaluation menu and choose result option, after start

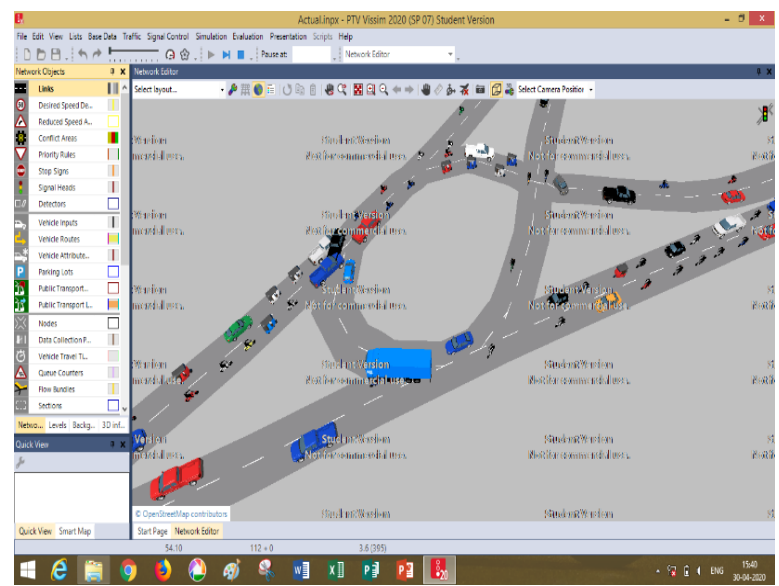

Fig 12 Running Simulation in VISSIM Software

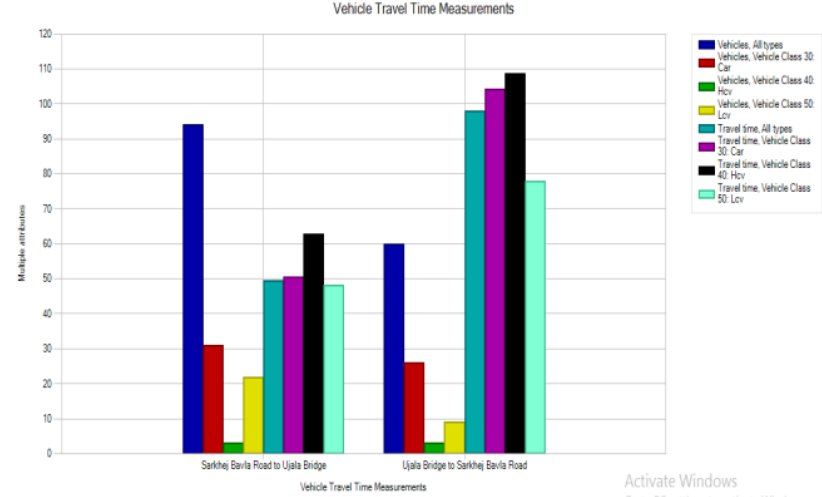

Fig 14 Vehicle Travel time Measurement for modified Route (Non-Elevated)

As per collected data and analyzed it in VISSIM software, we come to the point that there is Heavy two wheeler and Rickshaw flow at Ujala circle. But from Ujala circle to S.G. Highway there is not much congestion arise because of sufficient width of road is there. So to counteract heavy two wheelers and rickshaw flow from Ujala circle to Ujala Bridge and Ujala Circle to Sarkhej Bavla Road, one elevated over bridge is constructed over Ujala bridge. It should be noted that only two wheelers and rickshaw has to permit to use elevated over bridge. simulation and at the end of simulation process you will get travel time data. Copy that data in excel and prepare sheet.

Due to limitation of Student version of VISSIM software you would take maximum length of route is $1 \mathrm{~km}$ and simulation period is restricted to 600 second. Travel time graphs derived from data shown in Fig. 13, 14, 15.

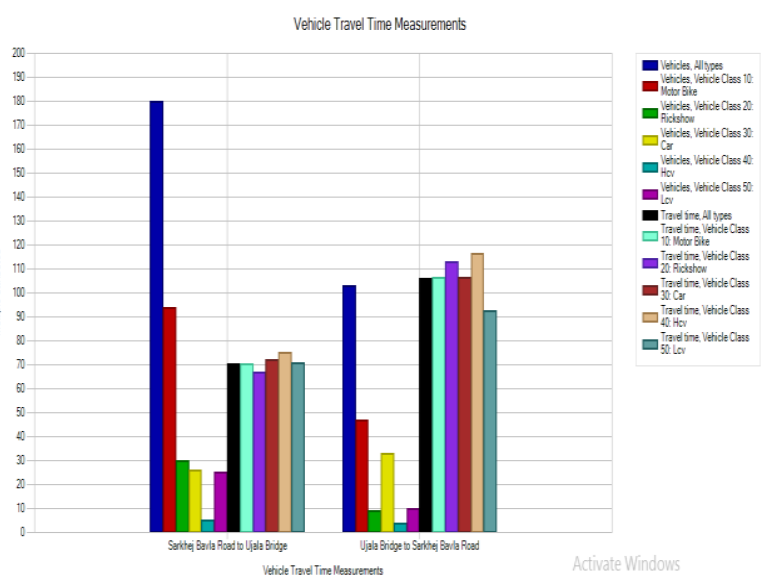

Fig 13 Vehicle Travel time Measurement for Current Route

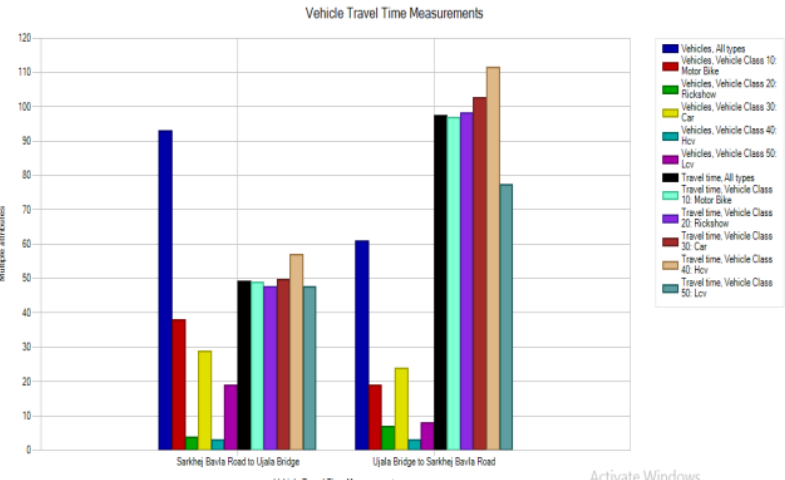

Fig 15 Vehicle Travel time Measurement for modified Route (Elevated)

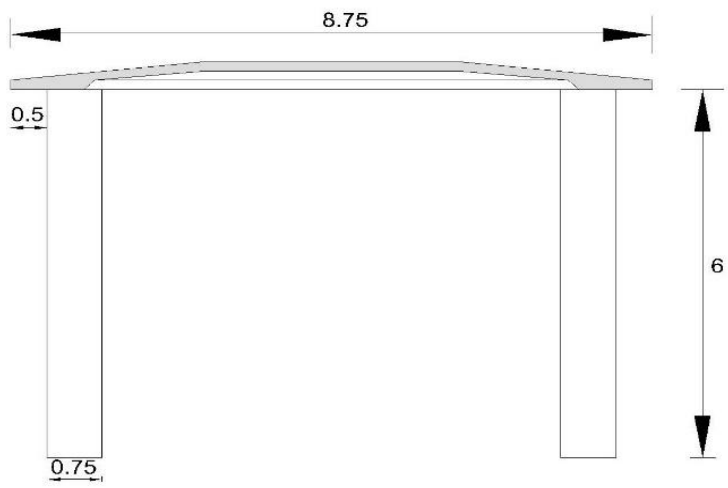

Fig 16 Section of Elevated over Bridge (All dimensions are in meter)

Published By:

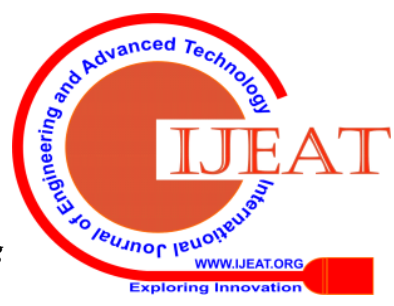




\section{Travel Time and Congestion Assessment Along Ujala Circle (S.G. Highway Ahmedabad)}

\section{CONCLUSION AND RESULTS}

One of the best way to reduce congestion is to traffic management on that area. Ujala circle to Sarkhej Bavla road consist uneven distribution of shops on either side as well as Ujala circle to Ujala Bridge does not have enough space so widening of road is not possible in both the case.

1) From classified volume count survey we observed that Total number of vehicles in term of PCU moving towards Sarkhej-Bavla road is highest (3280) during 12:00 to 01:00. Similarly Total number of vehicles in term of PCU moving towards Ujala Bridge is highest (2205) during 11:00 to 12:00. And Total number of vehicles in term of PCU moving towards S.G. Highway is highest (2657) during 06:00 to 07:00.

2) By performing moving observer survey we observed that moving from Ujala Circle to Santhal circle highest Journey time (4.48 min), Running time (3.14 min) and delay (1.34 min) observed during Evening trip also moving from Santhal circle to Ujala circle Highest Journey time (5.64 min), Running time (2.996 min) and delay (2.644 min) observed during Evening trip.

Similarly moving from Ujala Circle to Sarkhej circle highest Journey time (2.072 min), Running time (1.758 min) and delay (0.314 min) observed during Morning trip also moving from Sarkhej circle to Ujala circle Highest Journey time (1.996 min), Running time (1.076 min) and delay (0.92 min) observed during Morning trip.

And moving from Ujala Circle to Sanand chokdi highest Journey time (3.403 min), Running time (2.297 min) and delay (1.106 min) observed during Evening trip also moving from Sanand chokdi to Ujala circle Highest Journey time (3.453 min), Running time (2.239 min) and delay (1.214 min) observed during Evening trip.

3) From the Spot speed survey it has been derived that for flow towards Sarkhej-Bavla road $\mathrm{R}^{2}$ value of Flow-Density Graph 0.7617, Speed-Density Graph 0.6712, Speed-Flow Graph 0.3104.

Similarly for flow towards Ujala Bridge $\mathrm{R}^{2}$ value of Flow-Density Graph 0.7321, Speed-Density Graph 0.6875, Speed-Flow Graph 0.396.

Also for flow towards S.G. Highway $\mathrm{R}^{2}$ value of Flow-Density Graph 0.5398, Speed-Density Graph 0.635, Speed-Flow Graph 0.349.

4) From the VISIIM simulation model we observed that there is large amount of two wheelers and rickshaw flow at Ujala circle. So if we would construct Elevated over bridge having length of 225 meter laid over Ujala circle between Santhal circle and Sarkhej chokdi which permits only two wheelers and rickshaws flow then we could have huge control over congestion also restricted over large travel time due to delay.

If we think beyond this results we can also control congestion by convert non signalized intersection like Ujala circle to the signalized intersection and develop proper parking facilities.

\section{REFERENCES}

1. Dr. Tom V. Mathew (2014), Introduction of Transportation Engineering chapter 32, Transportation System Engineering Chapter 11, Transportation System engineering Lecture Notes about Congestion Studies, Transportation System Engineering, Chapter 35, IIT Bombay.
2. L.R. Kadiyali (2011) Transportation Planning, Khanna publication, Delhi-110006

3. Highway Engineering by Khanna and Justo, Nem Chand \& Bros Publication

4. Ahmedabad municipal Corporation Website http://ahmedabadcity.gov.in

\section{Ahmedabad-Wikipedia}

6. Revised Development plan 2021 www,auda.org.in

7. Ahmedabad Traffic Management and information control center (OPERATION DOCUMENT) by Ministry of Urban Development,

8. Vehicle populations by Commissionerate of Transport (Department of Port and Transport, Government of Gujrat), rtogujrat.gov.in

9. IRC-106-1990 Guidelines for Capacity of Urban Roads in Plain Area Published by the Indian Roads Congress

10. Highway Capacity Manual by Transportation Research Board (National Research Council)

11. Geometric Design Standards of Urban Roads in Plains, IRC 86-1983.

\section{AUTHORS PROFILE}

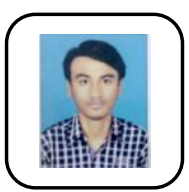

Vivek Mer is currently a last semester M.E. Student in the department of civil engineering, PG center of Transportation Engineering from L.D. College of Engineering Ahmedabad, Gujarat. L.D. College is one of the reputed college in Gujarat. He has received his B.E. Degree in Civil Engineering from Faculty of Technology and Engineering M.S. University Baroda (One of the finest college in Gujarat). He has also adequate knowledge about AutoCAD (2d+3d), 3d Max, V-Ray, and VISSIM Software.

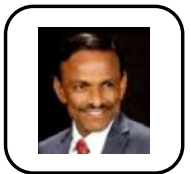

Dr. (prof.) V.R. Patel, at present working as an Associate professor in Civil Engineering Department at L.D. College of Engineering, Ahmedabad. He did his B.E.(Civil) from Sardar Patel University (Birla vishvakarma Mahavidyalaya), vallabh vidyanagar and M.E. Civil (Transportation Engineering) degree from Gujarat University (L.D. College of Engineering College), Ahmedabad. He did Ph.D. from Kadi Sarva Viswavidyalaya, Gandhinagar. He has more than 30 years of experience out of which 5 years in fieldworks and 25 years of teaching experience at UG and PG levels. He has carried out several consultancy projects successfully. He has coordinated few training programme/s. He is also associated in research projects related to Transportation Engineering and guided many students for their dissertation.

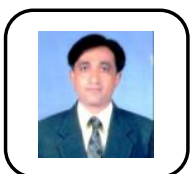

Dr. A.K. Patel is currently working as an Assistant Professor in Government polytechnic Ahmedabad. He has awarded for National Award in Best M.Tech Thesis in Civil Engineering, $2^{\text {nd }}$ prize, ISTE December 2009. He also got Dr. R.C.Sonpal Merit Gold Medal M.E. Transportation, Institute of Engineers, Ahmedabad 2009 and Gold medal, M.E. Transportation, GICEA, Ahmedabad, 2010. Apart from that he has more than 29 Years of teaching Experience and his Area of Interest are Transportation Engineering, Traffic Engineering, Pavement Design.
Published By:

Blue Eyes Intelligence Engineering \& Sciences Publication (C) Copyright: All rights reserved. 